\title{
Papel social do pensamento crítico
}

Paula Broeiro*

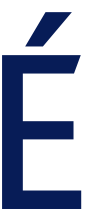

num olhar atento sobre a realidade profissional que nos surgem questões cujas respostas conduzem à atualização e à produção de conhecimento. O pensamento crítico, decorrente desse olhar atento, é complexo e ultrapassa a mera capacidade de analisar - inclui a compreensão de interações; a deteção de inconsistências; a resolução sistemática de problemas; a reflexão e a justificação de crenças e valores. ${ }^{1}$ Pressupõe, ainda, a reintegração da informação num todo, de preferência harmonioso. $\mathrm{O}$ pensamento crítico pode ajudar a construir conhecimento e a melhorar ou fortalecer argumentos.

Há quem afirme que ele dificulta a criatividade, porque integra regras da lógica e da racionalidade enquanto a criatividade exige atitude de rutura. ${ }^{1}$ Acredito que o pensamento crítico é compatível com o pensamento "fora da caixa", o desafio do consenso e a discordância. É, por isso, essencial à criatividade, pois permite analisar, ponderar e melhorar as ideias criativas. Este pensamento pode, ainda, ser descrito como o método científico aplicado ao quotidiano: identificação da questão, formulação de hipótese(s), pesquisa e adequação do modelo de resposta. ${ }^{2}$

Ao delinear as semelhanças entre o pensamento crítico e o método científico verifica-se que ambos são um processo de pensamento: intencional, aberto, rigoroso e de autocorreção. Neste pensar analítico e reflexivo se tem construído, criativamente, conhecimento. ${ }^{2}$ A ênfase na criatividade e contextualização afastam o pensamento da frieza da análise das evidências e apoia a construção do conhecimento num contexto social e cultural. Além disso, sugere a possibilidade de haver várias respostas e que o raciocínio e os processos de decisão clínica devem ser objeto de revisão cíclica. ${ }^{3}$

Diferentes olhares sobre a realidade geram diversidade e clarificam limites de intervenção no processo de prestação de cuidados. É no confronto de ideias com os

*Directora da Revista Portuguesa de Medicina Geral e Familiar outros que criamos espelho e identidade enquanto pessoas, profissionais e especialistas. As diferenças inerentes a cada médico, como as características pessoais (e.g., idade, género), a formação, a experiência profissional, a especialidade médica e o contexto de exercício influenciam a forma como se integra o conhecimento e, em consequência, como se decide. O raciocínio probabilístico influencia a decisão e justifica muitas vezes a diferente leitura da mesma realidade quando observada em contextos de exercício diferentes (e.g., Cuidados primários vs Cuidados secundários). ${ }^{4}$ Esta amplitude de variabilidade cria dificuldades à modelação do pensamento clínico.

Por mais que os teóricos humanistas do pensamento crítico enfatizem a subjetividade e a criatividade individual no pensamento, ele também está ligado a uma epistemologia construtivista. O contexto no qual o indivíduo pensa e constrói as suas formas de saber é social. $\mathrm{O}$ resultado desse pensamento e construção de saber não pode ser desligado dessa teia social em que se insere.

Nesta compreensão do pensamento e do conhecimento não há verdade absoluta, mas várias verdades socialmente produzidas e co-criadas. ${ }^{3}$ A produção de conhecimento implica a sua divulgação e pressupõe a necessidade de interação e feedback, ficando assim explícito o seu papel social.

Das características essenciais ao pensamento crítico destacam-se: a capacidade de aplicar evidência com imparcialidade, a organização e coerência do pensamento, a compreensão da diferença entre raciocínio e racionalização e a aplicação de modelos criativos de resolução de problemas. Em Medicina Geral e Familiar, a aplicação de evidência requer soluções não lineares e, porque nem sempre se dispõe de evidência robusta (proveniente de ensaios clínicos, controlados e aleatorizados) e/ou orientada para o paciente, tem o médico que utilizar a melhor evidência disponível. ${ }^{5}$ Além do viés de informação referido, muitas das decisões médicas têm subjacentes vieses de estimativa pro- 
babilística, como o da disponibilidade (e.g., sobreapreciação de casos frequentes ou graves e o inverso).

Na sequência do pensar criticamente sobre a Orientação Técnica n. ${ }^{0} 011 / 2013,{ }^{6}$ os autores do artigo $\mathrm{Su}$ plementação de iodo na pré-conceção, gravidez e amamentação: a recomendação e a Medicina baseada na inferência ${ }^{7}$ explicitaram a sua reflexão. Com esta publicação foi criada uma discordância salutar que motivou a publicação, nesta revista, de uma carta à diretora. Sendo um tema tangencial a, pelo menos, duas especialidades médicas, estamos certos de que, nesta discussão e confronto com outros (pares ou pessoas de quem cuidamos), tomamos consciência dos limites do conhecimento.

Como sabemos, o raciocínio clínico e a decisão são complexos e dependem do problema de saúde (e.g., prevalência e gravidade), da qualidade da informação de que dispomos, das características de quem cuidamos, da ponderação do custo/benefício da intervenção e, por último, mas não menos importante, das escolhas $\mathrm{da}(\mathrm{s})$ pessoa(s) de quem cuidamos. ${ }^{8}$

Em Medicina Geral e Familiar, este pensar, crítico e construtivo, que potencia a qualidade das decisões clínicas e a capacitação das pessoas de quem cuidamos, com consequentes ganhos em eficiência e satisfação, só se consegue com tempo e disponibilidade para a reflexão.

\section{REFERÊNCIAS BIBLIOGRÁFICAS}

1. Web CT. What is critical thinking? [Internet]. The University of Hong
Kong; 2004 [updated 2014 Jan 1].Available from: http://philosophy.hku. hk/think/critical/ct.php?print=1

2. Karakas SL. Creative and critical thinking in the arts and sciences: some examples of congruence. 2010;2010:1-9. Available from: http://forumonpublicpolicy.com/spring2010.vol2010/spring2010archive/karakas.pdf

3. Kahlke R, White J. Critical thinking in health sciences education: considering 'Three Waves'. Creat Educ. 2013;4(12A):21-9. Available from: http://www.scirp.org/journal/PaperDownload.aspx?DOI=10.4236/ce.2 $013.412 \mathrm{~A} 1004$

4. Smith M, Higgs J, Ellis E. Factors influencing clinical decision making. In Clinical reasoning and clinical decision making: nature and context. Sydney: Elsevier/Butterworth Heinemann; 2008. p. 89-100. Available from: http://www.elsevierhealth.com/media/us/samplechapters/ 9780750688857/9780750688857.pdf

5. Dynamed. Step evidence-based methodology [Internet]. Washington: EBSCOhost.com; 2014. Available from: https://dynamed.ebscohost. com/content/7-step-process

6. Direção-Geral da Saúde. Aporte de iodo em mulheres na preconcecao, gravidez e amamentacao: orientação n. ${ }^{\circ}$ 11/2013, de 26/08/2013. Lisboa: DGS; 2013. Available from: http://www.dgs.pt/?cr=24648. Portuguese

7. Silva F, Agostinho-Santos J. Suplementacao de iodo na pre-concepcao, gravidez e amamentacao: a recomendacao e a medicina baseada na inferencia [lodine supplementation before and during pregnancy and breastfeeding: recommendations and inference-based-medicine]. Rev Port Clin Geral. 2013;29(6)403-8. Portuguese

8. Coulter A, Ellins J. Patient-focused interventions: a review of the evidence. London: The Health Foundation; 2006. ISBN 0954896815. Available from: http://www.health.org.uk/public/cms/75/76/313/526/Patient focused interventions.pdf? realName $=$ juNCmR.pdf

\section{ENDEREÇO PARA CORRESPONDÊNCIA}

director@rpcg.apmcg.pt 